\title{
Oxidation of Glyoxylic Acid by Cerium(IV): Oxygen-Induced Enhancement of the Primary Radical Concentration
}

\author{
Bettina Neumann, ${ }^{\dagger}$ Oliver Steinbock, Stefan C. Miiller,,,+ \\ Department of Chemistry, Florida State University, Tallahassee, Florida 32306-3006, and Department of \\ Chemistry, West Virginia University, Morgantown, West Virginia 26506
}

Received: January 30, $1996^{\otimes}$

\begin{abstract}
In order to help understand the role of oxygen in $\mathrm{Ce}(\mathrm{IV})$-induced oxidation of small carbonic acids, we investigated the reaction of glyoxylic acid $(\mathrm{HCOCOOH})$ and $\mathrm{Ce}(\mathrm{IV})$ in $1 \mathrm{M}$ sulfuric acid. Spectrophotometric data showed that in excess of glyoxylic acid the consumption of Ce(IV) obeys pseudo-first-order kinetics, with a rate constant of $8.8 \mathrm{~L} \mathrm{~mol}^{-1} \mathrm{~s}^{-1}$ at $25{ }^{\circ} \mathrm{C}$ and an activation energy of $80 \mathrm{~kJ} \mathrm{~mol}^{-1}$. Rapid-flow EPR measurements revealed an approximately 1:2:1 triplet with a $g$ value of $2.0071 \pm 0.0005$ and a hyperfine splitting of $7.1 \pm 0.2 \mathrm{G}$, assignable to the primary radical formed by abstraction of a hydrogen atom from hydrated glyoxylic acid. The rate constant for the anaerobic self-decay of the radical was measured as approximately $3.7 \times 10^{9} \mathrm{~L} \mathrm{~mol}^{-1} \mathrm{~s}^{-1}$. Surprisingly, oxygen had no effect on the Ce(IV) kinetics, while the radical decay was significantly inhibited under aerobic conditions (ratio of experimental rate constants $\approx 6.3$ ). Amperometric measurements revealed accompanying oxygen consumption. Analyses based on numerical simulations show that the observed oxygen-induced increase in radical concentration cannot be explained in the framework of standard autooxidation mechanisms. An alternative reaction scheme is suggested which reproduces the observed aerobic radical kinetics and which thus could be relevant to similar oxidation reactions.
\end{abstract}

\section{Introduction}

Over the past several decades the oxidation of organic compounds by ceric ions has been the subject of numerous studies. ${ }^{1}$ However, most reaction mechanisms are highly complex and thus not yet fully understood, possibly because of the lack of direct experimental data on the involvement of radical species. A striking example is the $\mathrm{Ce}(\mathrm{IV})$ oxidation of malonic acid $\left(\mathrm{CH}_{2}(\mathrm{COOH})_{2}\right)$ which was first investigated at least as early as $1930 .^{2}$ It was generally considered that in this reaction the first step was the abstraction of a hydrogen atom by Ce(IV) to form the malonyl radical, which then decayed by disproportionation. ${ }^{3}$ In 1994, however, Gao et al. ${ }^{4}$ demonstrated that the first stable product was ethanetetracarbonic acid, formed by dimerization of the primary (malonyl) radical. Thus, their findings were in contrast to the generally assumed radical disproportionation model. The ceric oxidation of malonic acid is of particular interest because of its relevance for the widely studied Belousov-Zhabotinsky ${ }^{5}$ (BZ) reaction. ${ }^{6-8}$ It is also known that the dynamics of the $\mathrm{BZ}$ reaction as well as the kinetics of the oxidation of malonic acid are strongly influenced by molecular oxygen. ${ }^{9-13}$ For these aerobic reaction systems, the formation of the peroxydicarboxymethyl radical had been long postulated as an important intermediate but only very recently were we able to identify and characterize this species. ${ }^{14}$ In the case of the ceric oxidation of malonic acid, we also found that the kinetics of this radical can be readily explained in terms of a standard autooxidation mechanism. On the other hand, it is known that peroxy radicals of small hydrocarbon species are not easily detected. It was thus of interest to probe the fundamental question whether the formation of peroxy radicals is necessarily the key process of aerobic oxidation reactions of small carboxylic acids.

\footnotetext{
${ }^{\dagger}$ Max-Planck-Institut für molekulare Physiologie, Rheinlanddamm 201, D-44139 Dortmund, Germany.

‡ Otto-von-Guericke-Universität Magdeburg, Institut für Experimentelle Physik, Universitätsplatz 2, 39106 Magdeburg, Germany.

${ }^{\otimes}$ Abstract published in Advance ACS Abstracts, June 15, 1996.
}

The formation of peroxy radicals is considered to be part of the chain propagation in the generally assumed mechanism for autooxidation reactions: ${ }^{15}$

initiation: formation of $\mathrm{R}^{\bullet}$ (e.g. by reaction with a metal catalyst)

propagation:

$$
\begin{gathered}
\mathrm{R}^{\bullet}+\mathrm{O}_{2} \rightarrow \mathrm{ROO}^{\bullet} \\
\mathrm{ROO}^{\bullet}+\mathrm{RH} \rightarrow \mathrm{ROOH}+\mathrm{R}^{\bullet}
\end{gathered}
$$

termination: $\quad \mathrm{ROO}^{\bullet}+\mathrm{ROO}^{\bullet} \rightarrow$ nonradical products $+\mathrm{O}_{2}$

where $\mathrm{RH}$ represents the organic substrate, $\mathrm{R}^{\bullet}$ the primary radical, $\mathrm{ROO}^{*}$ the peroxy radical, and $\mathrm{ROOH}$ the hydroperoxide of $\mathrm{RH}$ that might further react with present metal ions.

Here we present results on the ceric oxidation of glyoxylic acid (GOA; $\mathrm{HCOCOOH})$ under aerobic and anaerobic conditions as obtained from spectrophotometric, rapid-flow electron paramagnetic resonance (EPR), amperometric measurements, and numerical simulations. Glyoxylic acid was selected as a test case for the standard model of autooxidation for several reasons. First, it is one of the smallest carbonic acids that can be oxidized by $\mathrm{Ce}(\mathrm{IV})$. Second, GOA is possibly an intermediate in the ceric oxidation of malonic acid under oxygen: Recombination of the peroxymalonyl radical could form tartronic acid $\left(\mathrm{HCOH}(\mathrm{COOH})_{2}\right)$ and either GOA or mesoxalic acid $\left(\mathrm{CO}(\mathrm{COOH})_{2}\right)$ as the immediate decay products. GOA has also been postulated to be a stable intermediate in the $\mathrm{Ce}$ (IV) oxidation of tartronic acid and can substitute malonic acid as the organic substrate for oscillating BZ reactions. ${ }^{16-18}$ Hence, kinetic data on the oxidation of GOA by $\mathrm{Ce}(\mathrm{IV})$ should provide important information for a more complete understanding of the aerobic oxidation of malonic acid and other related reactions (as for example the BZ reaction).

In one of the earlier studies of the reaction between Ce(IV) and glyoxylic acid Jwo and Noyes ${ }^{3}$ measured the stoichiometric ratio $\Delta[\mathrm{Ce}(\mathrm{IV})] / \Delta[\mathrm{GOA}]$ as 1.9 . Furthermore, formic acid ( $\mathrm{HCOOH}, \mathrm{FA})$ and $\mathrm{CO}_{2}$ were identified as the reaction products. 
These results were obtained under unspecified atmospheric conditions. Nevertheless, these findings suggest the following simple reaction mechanism involving the primary radical ${ }^{\circ} \mathrm{CO}$ $(\mathrm{COOH})$ :

$$
\begin{aligned}
& \mathrm{HCOCOOH}+\mathrm{Ce}(\mathrm{IV}) \rightarrow{ }^{\bullet} \mathrm{COCOOH}+\mathrm{Ce}(\mathrm{III})+\mathrm{H}^{+} \\
& { }^{\cdot} \mathrm{COCOOH}+{ }^{\cdot} \mathrm{COCOOH}+\mathrm{H}_{2} \mathrm{O} \rightarrow \\
& \mathrm{HCOCOOH}+\mathrm{HCOOH}+\mathrm{CO}_{2}
\end{aligned}
$$

To our knowledge the radical in this reaction $\left({ }^{\circ} \mathrm{COCOOH}\right)$ has neither been identified nor kinetically studied so far. However, glyoxylic acid related radicals produced by flash photolysis ${ }^{18,19}$ have been detected earlier: Using EPR spectroscopy Steenken et al. ${ }^{18}$ reported the detection of radicals formed from photolysis of GOA at $\mathrm{pH} 3$ and higher. At lower $\mathrm{pH}$, however, no radicals were observed after irradiation unless the sensitizer acetone was added to the solution. We were intrigued by the fact that in contrast to the case of malonic acid, the possibility of an intermediate formed by the dimerization of $\mathrm{GOA}^{\bullet}$ and any role of oxygen were not discussed. The present study suggests that these are indeed key processes in the oxidation of GOA by $\mathrm{Ce}$ (IV) and thus likely in other related systems.

\section{Experimental Section}

Kinetic and stoichiometric measurements of Ce(IV) were performed utilizing a Hewlett-Packard HP8452 diode array spectrophotometer. The time dependence of the $\mathrm{Ce}$ (IV) concentration was followed at a wavelength of $320 \mathrm{~nm}$. Kinetic experiments with initially added Ce(III) were carried out with anhydrous cerous (Ce(III)) sulfate (Fluka, purum). The stoichiometry was determined by photometric analysis of the residual $\mathrm{Ce}(\mathrm{IV})$ concentration approximately one day after initiation of the reaction. These experiments were performed at a wave length of $398 \mathrm{~nm}$ due to higher $\mathrm{Ce}$ (IV) concentrations. In all experiments $\mathrm{Ce}(\mathrm{IV})\left(\mathrm{SO}_{4}\right)_{2} \times 4 \mathrm{H}_{2} \mathrm{O}$ (Merck) and GOA (Fluka) were used. Arrhenius parameters were obtained from variable temperature measurements using a thermostated water bath.

EPR measurements were made with a Bruker ER200D $\mathrm{X}$-band $(9.5 \mathrm{GHz})$ EPR spectrometer and a rapid flow attachment. ${ }^{14,20}$ The two reactant solutions $([\mathrm{GOA}]=1.0 \mathrm{M}$ and $[\mathrm{Ce}-$ $\left.\left(\mathrm{SO}_{4}\right)_{2}\right]=14.0 \mathrm{mM}$, both in $\left.1 \mathrm{M} \mathrm{H}_{2} \mathrm{SO}_{4}\right)$ were pumped to a quartz flat cell equipped with a T-shaped mixing device (pump used: Gilson Miniplus3). The quartz flow cell (Wilmad WG804-Q) was mounted in the EPR cavity and had an active and a dead volume of $125 \mu \mathrm{L}$ and $<50 \mu \mathrm{L}$, respectively. The stable radicals 4-hydroxy-2,2,6,6-tetramethylpiperidine- $N$-oxyl (TEMPO) and 1,1-diphenyl-2-picrylhydrazyl (DPPH) (Aldrich) were used as standards for the determination of radical concentrations and $g$ values. The microwave frequency was measured with a Hewlett-Packard (HP5420) digital frequency counter and the magnetic field was calibrated with a gaussmeter for measuring the $g$ values and hyperfine couplings.

Oxygen consumption was measured amperometrically using a Clark-type electrode. Prior to the experiments the electrode was calibrated utilizing solutions of known oxygen concentration (solutions were equilibrated by the means of a gas mixing pump).

A $270 \mathrm{MHz}$ FT NMR system (JNM-EX270, JEOL) was used for the identification of the reaction products. Samples of 0.6 $\mathrm{M} \mathrm{Ce}(\mathrm{IV})\left(\mathrm{NH}_{4}\right)_{2}\left(\mathrm{NO}_{3}\right)_{6}$ (Fluka) and $0.6 \mathrm{M} \mathrm{GOA}$ in $1 \mathrm{M}$ sulfuric acid were allowed to react at room temperature for more than $12 \mathrm{~h}$. Proton-decoupled ${ }^{13} \mathrm{C}$ NMR spectra were then taken with dioxane $(67.4 \mathrm{ppm})$ as an internal standard. The spectra
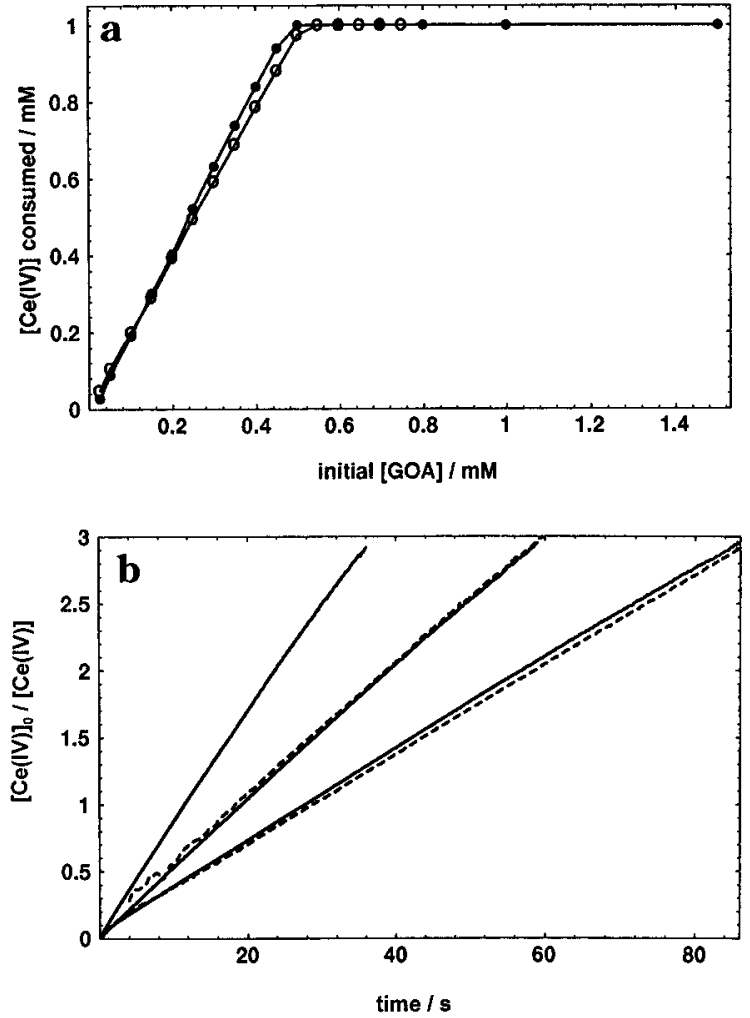

Figure 1. Spectrophotometric data for the Ce(IV) oxidation of glyoxylic acid. (a) Dependence of the amount of reduced Ce(IV) on the initial concentration of glyoxylic acid. Open circles: aerobic conditions; solid circles: anaerobic conditions. (b) Semilogarithmic plot of the $\mathrm{Ce}(\mathrm{IV})$ concentration evolution during the reaction at 25.0 ${ }^{\circ} \mathrm{C}$. Data were obtained under anaerobic (solid lines) and aerobic $\left(\left[\mathrm{O}_{2}\right]_{0}\right.$ $\approx 1.0 \mathrm{mM}$; dashed lines) conditions. Initial concentrations: [Ce(IV)] $=0.1 \mathrm{mM},[\mathrm{GOA}]=4.0,6.0,10.0 \mathrm{mM},\left[\mathrm{H}_{2} \mathrm{SO}_{4}\right]=1 \mathrm{M}$.

revealed three peaks with the chemical shifts: $174.1 \mathrm{ppm}(1)$, $166.8 \mathrm{ppm}$ (2), and $87.2 \mathrm{ppm}$ (3). Peak (2) was identified as formic acid, while signals (1) and (3) correspond to residual glyoxylic acid. From comparison with literature spectra and numerical predictions, peak (1) and (3) were assigned to the hydrated form $\left(\mathrm{HCOCOOH} \times \mathrm{H}_{2} \mathrm{O}\right)$ of glyoxylic acid. ${ }^{21}$

\section{Results}

Stoichiometric Analysis. With the view of understanding the overall $\mathrm{Ce}(\mathrm{IV})-\mathrm{GOA}$ reactivity we first carried out measurements on the reaction stoichiometry under well-defined aerobic and anaerobic conditions. Figure 1a shows the consumption of $\mathrm{Ce}(\mathrm{IV})$ for various initial GOA concentrations. The consumption was measured spectrophotometrically as the difference between the initial (here $1.0 \mathrm{mM}$ ) and the residual Ce(IV) concentration (wavelength $398 \mathrm{~nm}$ ). The applicability of Beer's law was checked in additional experiments which revealed no significant deviations from a linear dependence between absorbance and [Ce(IV)]. The curves in Figure 1a consist of two linear segments. The horizontal segments arise from experiments in which the initial GOA concentration was too high for a complete reaction with $1 \mathrm{mM} \mathrm{Ce}(\mathrm{IV})$, while the points on the tilted segment represent experiments with no residual GOA. Based on these data we measured the stoichiometric ratio $\Delta[\mathrm{Ce}(\mathrm{IV})] / \Delta[\mathrm{GOA}]$ under aerobic and anaerobic conditions as $1.98 \pm 0.1$ and $2.02 \pm 0.1$, respectively. The results obtained indicate no significant dependence of the stoichiometry on the atmospheric conditions.

This result is important because it implies a basic constraint on the possible mechanisms of the reaction. Note that the 

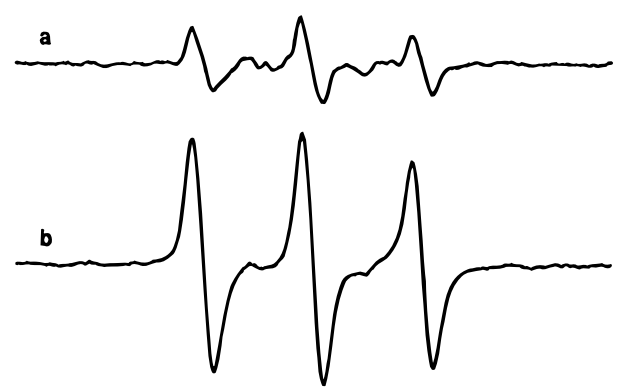

$3 4 \longdiv { 3 0 }$

3450

3460

- Gauss

Figure 2. EPR spectra observed from the reaction between Ce(IV) and glyoxylic acid under anaerobic (a) and aerobic (b) conditions. Both spectra were obtained under identical experimental conditions. Initial concentrations: $[\mathrm{Ce}(\mathrm{IV})]=7.0 \mathrm{mM},[\mathrm{GOA}]=0.5 \mathrm{M},\left[\mathrm{H}_{2} \mathrm{SO}_{4}\right]=1$ M.

identical stoichiometry obtained from anaerobic and aerobic measurements can be due to the same major reaction pathway but might as well be caused by different pathways.

Reaction Kinetics of Ce(IV). The kinetics of the oxidation of GOA by $\mathrm{Ce}$ (IV) was studied in excess of GOA. Figure $1 \mathrm{~b}$ shows the photometrically detected decay of $\mathrm{Ce}(\mathrm{IV})$ for three different GOA concentrations. The curves reveal only small deviations from the expected linear dependence. Furthermore, we found no systematic differences between the cerium kinetics under aerobic and anaerobic conditions. The pseudo-first-order value of $k_{1}$ at $25.0^{\circ} \mathrm{C}$ was calculated from various experimental rate constants as $8.8 \pm 0.2 \mathrm{~L} \mathrm{~mol}^{-1} \mathrm{~s}^{-1}$.

For probing the reaction further we measured the temperature dependence of $k_{1}$ as summarized below. The Arrhenius plot of $\ln k_{1}$ vs $1 / T$ was analyzed over the temperature range of 14$40{ }^{\circ} \mathrm{C}$. The initial concentration of $\mathrm{Ce}(\mathrm{IV})$ in all experiments was $0.1 \mathrm{mM}$, while the initial GOA concentration was varied between 4.0 and $20.0 \mathrm{mM}$. The Arrhenius plot revealed a linear dependence, allowing the determination of the activation energy $E_{\mathrm{a}}$ and the preexponential factor $A$ of reaction $(\mathrm{R} 1)$ to be $E_{\mathrm{a}} \approx$ $80 \mathrm{~kJ} \mathrm{~mol}^{-1}$ and $A \approx 1.4 \times 10^{15} \mathrm{~L} \mathrm{~mol}^{-1} \mathrm{~s}^{-1}$. The measured activation energy of $80 \mathrm{~kJ} \mathrm{~mol}^{-1}$ is in the typical range for ceric oxidation reactions of organic acids; corresponding values for malonic (MA) and tartronic acid (TA) are 46 and $74 \mathrm{~kJ} \mathrm{~mol}^{-1}$, respectively. ${ }^{3}$ The trend $E_{\mathrm{a}}(\mathrm{MA})<E_{\mathrm{a}}(\mathrm{TA})<E_{\mathrm{a}}(\mathrm{GOA})$ reflects the expected significance of steric factors.

Additional measurements were carried out to study the possible back reaction between $\mathrm{Ce}$ (III) and reaction products of GOA. In these experiments the initial concentrations of $\mathrm{Ce}$ (IV) and GOA were 0.1 and $6.0 \mathrm{mM}$, respectively. It was found that addition of $\mathrm{Ce}$ (III) in concentration of $<1 \mathrm{mM}$ caused no detectable effects on the kinetics. Higher concentrations of $\mathrm{Ce}$ (III) (10 and $20 \mathrm{mM})$, however, slightly decelerated the reaction, resulting in small deviations from the simple exponential decay. Since the overall effect of $\mathrm{Ce}$ (III) on the reaction was considered to be rather small, no further quantitative analysis was carried out.

EPR Measurements. a. Radical Identification. Since an important goal of this study was to directly detect and identify any free-radical involvement and the radical species were expected to be short-lived, we utilized the fast-flow EPR technique as described in the Experimental Section. Figure 2 shows typical EPR spectra obtained from reaction mixtures of GOA and $\mathrm{Ce}(\mathrm{IV})$ that were purged with nitrogen (Figure 2a) and oxygen (Figure 2b), respectively. In both cases the major feature is the approximately 1:2:1 triplet, with a hyperfine splitting of $7.1 \pm 0.2 \mathrm{G}$. The observed deviation from the 1:2:1 line shape under oxygen (Figure $2 b$ ) can be ascribed to the $m_{\mathrm{I}^{-}}$ dependent line broadening and microwave power saturation effects, as deduced from several detailed measurements. The $g$ values was measured as $2.0071 \pm 0.0005$. These features imply that the radical's unpaired electron is delocalized (at least partially) over a heavy-atom framework involving two magnetically equivalent protons. Further clues to radical identification were derived from the fact that the radical is not likely to be of alkoxy or peroxy type, because in that case the $g$ value difference from $g=2.0027$ would be an order of magnitude larger while the proton hyperfine coupling would be significantly (about $50 \%$ ) smaller. $^{22}$ Another helpful clue was that Ce(III) complexation leads to an increase in $g$ values. For example, the $g$ value of the $\mathrm{HO}_{2}{ }^{\bullet}$ radical increases from 2.0140 to 2.0180 on $\mathrm{Ce}(\mathrm{III})$ complexation. ${ }^{23,24}$ Generally, it is expected that $\mathrm{Ce}$ (III) bonds to the radical via the $\mathrm{CO}$ oxygens. Based on these arguments we tentatively assign the observed triplet to the following radical complex, formed by hydrogen abstraction from the hydrated form of glyoxylic acid:<smiles>[CH][C@H](Cl)OC(O)C(=O)O</smiles>

b. Oxygen Effect on Radical Concentration. A significant observation from the results presented in Figure 2, a and b, is that admission of oxygen to the GOA/Ce(IV) reaction system leads to a significant increase in the radical signal (about a factor of 3 under the given conditions) without any new EPR peak. This is in contrast to the case of malonic acid where oxygen exposure caused a rapid decrease in the malonyl radical concentration until oxygen was entirely consumed, with concomitant formation of the peroxy radical. ${ }^{14}$ As will be shown in the following, this unexpected difference in radical concentrations can be attributed to an additional oxygen-induced pathway in the reaction mechanism.

c. Radical Kinetics. The radical decay kinetics were monitored under anaerobic as well as aerobic conditions. These measurements were performed using the EPR stopped-flow technique with the initial concentrations and apparatus as described in the Experimental Section. Figure 3a shows the decay curve for an anaerobic (i.e., nitrogen equilibrated) reaction mixture. Based on the reactions R1 and R2 we expect a secondorder self-decay of the radical that is described by

$$
\mathrm{d}\left[\mathrm{GOA}^{\bullet}\right] / \mathrm{d} t=k_{1}[\mathrm{GOA}]_{0}[\mathrm{Ce}(\mathrm{IV})]-2 k_{2}\left[\mathrm{GOA}^{\bullet}\right]^{2}
$$

if GOA is in excess (i.e., its initial concentration, $[\mathrm{GOA}]_{0} \gg$ [Ce(IV)]). Moreover, spectrophotometric measurements showed that $[\mathrm{Ce}(\mathrm{IV})]$ obeys a simple first-order equation

$$
[\mathrm{Ce}(\mathrm{IV})]=[\mathrm{Ce}(\mathrm{IV})]_{0} \exp \left(-k_{\exp } t\right)
$$

with the initial concentration $[\mathrm{Ce}(\mathrm{IV})]_{0}$ and the experimental rate constant $k_{\exp }=[\mathrm{GOA}]_{0} k_{1}$. Further, assuming a steadystate radical concentration, i.e., $\mathrm{d}\left[\mathrm{GOA}^{\bullet}\right] / \mathrm{d} t=0$, eqs 1 and 2 yield

$$
\left[\mathrm{GOA}^{\bullet}\right]=\left\{\left([\mathrm{Ce}(\mathrm{IV})]_{0} k_{\exp }\right) /\left(2 k_{2}\right)\right\}^{1 / 2} \exp \left(-0.5 k_{\exp } t\right)
$$

Hence, the radical concentration is expected to decrease with the rate $0.5 k_{\text {exp. }}$ In order to test this prediction we first utilized the spectrophotometric data to calculate $k_{\exp }$ for the conditions of the EPR stopped-flow experiment (Figure 3a). This value was found to be $k_{\exp }=4.4 \mathrm{~s}^{-1}$. We then used this $k_{\exp }$ and eq 3 to predict the time dependence of the radical decay. The 

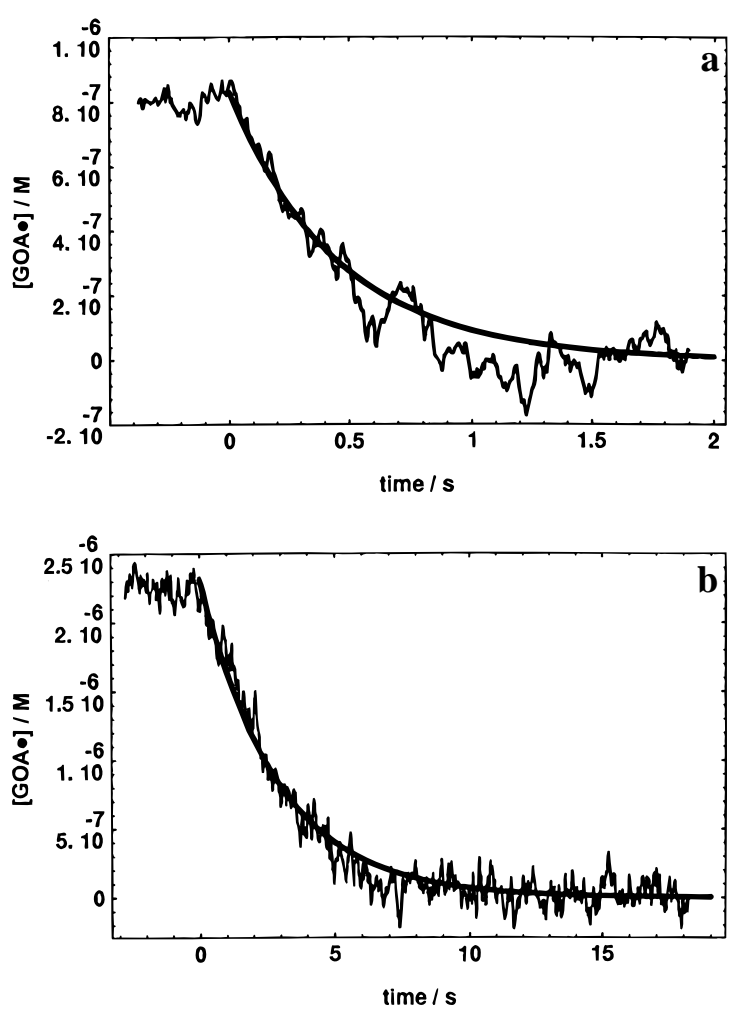

Figure 3. Experimental EPR signal decay and calculated curves for the $\mathrm{GOA}^{\bullet}$ kinetics under anaerobic (a) and aerobic $\left(\mathrm{b},\left[\mathrm{O}_{2}\right]_{0} \approx 1.0 \mathrm{mM}\right)$ conditions. Initial concentrations: $[\mathrm{Ce}(\mathrm{IV})]=7.0 \mathrm{mM},[\mathrm{GOA}]=0.5$ M. Calculated curves represent an exponential dependence with experimental rate constants: $k_{\text {exp }}=4.4 \mathrm{~s}^{-1}$ (a, cf. eq 3), $k_{\text {exp }}=0.35$ $\mathrm{s}^{-1}(\mathrm{~b})$.

TABLE 1: Experimental Values of the Rate Constant $\boldsymbol{k}_{\mathbf{2}}$ for Different Initial Concentrations of Glyoxylic Acid ${ }^{a}$

\begin{tabular}{ccccc}
\hline$[\mathrm{GOA}]_{0} / \mathrm{M}$ & {$[\mathrm{Ce}(\mathrm{IV})]_{\mathrm{f}} / \mathrm{mM}$} & $k_{\mathrm{exp}} / \mathrm{s}^{-1}$ & {$\left[\mathrm{GOA}^{\bullet}\right]_{\mathrm{fl}} / \mu \mathrm{M}$} & $k_{2} / \mathrm{L} \mathrm{mol}^{-1} \mathrm{~s}^{-1}$ \\
\hline 0.1 & 4.92 & 0.88 & 0.75 & $3.9 \times 10^{9}$ \\
0.2 & 3.46 & 1.77 & 0.82 & $4.5 \times 10^{9}$ \\
0.3 & 2.43 & 2.65 & 1.02 & $3.1 \times 10^{9}$ \\
0.4 & 1.71 & 3.53 & 0.98 & $3.1 \times 10^{9}$ \\
0.5 & 1.20 & 4.41 & 0.83 & $3.8 \times 10^{9}$
\end{tabular}

${ }^{a}$ The table summarizes data that was used to derive $k_{2}$ on the basis of eq 4. Differences in $k_{2}$ mainly reflect the experimental error in the determination of $\left[\mathrm{GOA}^{*}\right]_{\mathrm{fl}}$ from the EPR signals.

dashed curve in Figure 3a shows this calculated behavior, which can be seen to be in good agreement with the observed EPR signal decay. These results thus strongly support our initial hypothesis that the radical consumption is caused by a secondorder self-decay.

Equation 3 also enabled us to measure the rate constant $k_{2}$. By defining $\left[\mathrm{GOA}^{\bullet}\right]_{\mathrm{fl}}$ and $[\mathrm{Ce}(\mathrm{IV})]_{\mathrm{fl}}$ as the actual concentrations of $\mathrm{GOA}^{\bullet}$ and $\mathrm{Ce}(\mathrm{IV})$ established during the EPR flow experiment, we find that

$$
k_{2}=\left([\mathrm{Ce}(\mathrm{IV})]_{\mathrm{fl}} k_{\mathrm{exp}}\right) /\left(2\left[\mathrm{GOA}^{\bullet}\right]_{\mathrm{fl}}{ }^{2}\right)
$$

$[\mathrm{Ce}(\mathrm{IV})]_{\mathrm{fl}}$ can be calculated from eq 2 by considering the residence time of the flow system $\left(t_{\mathrm{r}}=0.4 \mathrm{~s}\right)$ as the reaction time $t$. The radical concentration $\left[\mathrm{GOA}^{\bullet}\right]_{\mathrm{fl}}$ was measured in numerous EPR experiments and calibrated by comparison with the EPR signal of 4-hydroxy-2,2,6,6-tetramethylpiperidine- $N$ oxyl. Table 1 summarizes the results for $k_{2}$ obtained under five different experimental conditions at $25{ }^{\circ} \mathrm{C}$. The entries for $k_{2}$ in Table 1 show reasonable consistency with the average value of $k_{2}=3.7 \times 10^{9} \mathrm{~L} \mathrm{~mol}^{-1} \mathrm{~s}^{-1}$. Considering the error due to
TABLE 2: Experimental Values of the Oxygen Consumption for Several Initial Concentrations of GOA and $\mathrm{Ce}(\mathrm{IV})^{a}$

\begin{tabular}{cccc}
\hline$[\mathrm{GOA}]_{0} / \mathrm{M}$ & {$[\mathrm{Ce}(\mathrm{IV})]_{0} / \mathrm{mM}$} & consumed $\left[\mathrm{O}_{2}\right] / \mathrm{mM}$ & $\Delta[\mathrm{Ce}(\mathrm{IV})] / \Delta\left[\mathrm{O}_{2}\right]$ \\
\hline 0.2 & 0.70 & 0.03 & 23 \\
0.2 & 1.40 & 0.05 & 28 \\
0.4 & 0.42 & 0.03 & 13 \\
0.4 & 0.70 & 0.05 & 15 \\
0.4 & 0.98 & 0.07 & 14 \\
0.4 & 1.40 & 0.09 & 16 \\
0.4 & 1.96 & 0.11 & 18
\end{tabular}

${ }^{a}$ The initial concentration of oxygen was kept constant at $\left[\mathrm{O}_{2}\right]_{0} \approx$ $0.15 \mathrm{mM}$.

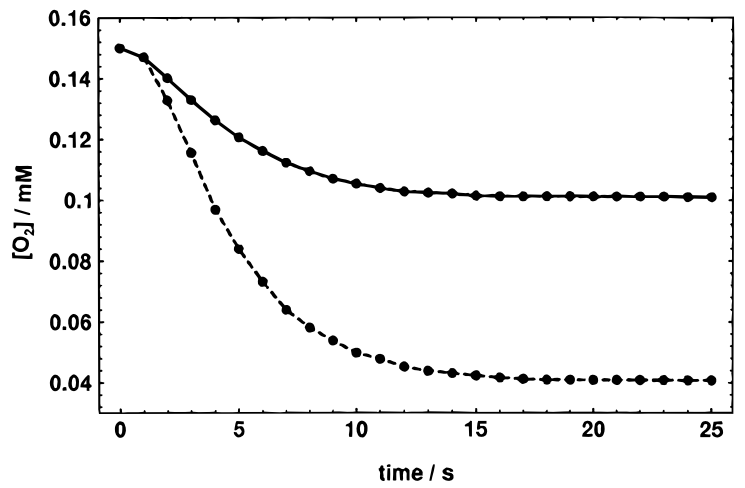

Figure 4. Two examples of oxygen consumption obtained from amperometric measurements. Initial concentrations: $[\mathrm{GOA}]=0.2 \mathrm{M}$, $[\mathrm{Ce}(\mathrm{IV})]=1.4 \mathrm{mM}$ (top curve, solid line), $[\mathrm{GOA}]=0.4 \mathrm{M},[\mathrm{Ce}(\mathrm{IV})]$ $=1.96 \mathrm{mM}$ (bottom curve, dashed line).

the EPR signal integration and that in the residence time $t_{\mathrm{r}}$ we estimate the relative error of $k_{2}$ as $\pm 30 \%$.

Figure $3 \mathrm{~b}$ shows a characteristic example for the radical decay under aerobic conditions. In these experiments both of the stock solutions were equilibrated with oxygen for at least $30 \mathrm{~min}$ prior to the start of the measurement. The oxygen concentration was estimated as $1.0 \times 10^{-3} \mathrm{M}$. Concentrations, sample temperature, and EPR parameters were the same as in the previous experiments (Figure 3a). The decreasing radical concentration obeys a simple exponential function with an experimental rate constant $k_{\exp }=0.35 \mathrm{~s}^{-1}$, in contrast to the value of $0.5 \times 4.4$ $\mathrm{s}^{-1}$ under anaerobic conditions. In the presence of oxygen, therefore, the radical decay is significantly inhibited: The average ratio of the experimental rate constants under anaerobic and aerobic conditions was found to be 6.3. This result implies that the radical decay inhibition is essentially the source of the observed oxygen influence on the intensity of the EPR signal (Figure 2a,b), i.e., increased radical accumulation under aerobic conditions.

Oxygen Consumption Measurements. Since the oxygen enhancement of radical concentration points toward a direct consumption of oxygen during the reaction, we performed systematic measurements of the oxygen concentration using a Clark electrode. Table 2 summarizes the total oxygen consumption for various initial Ce(IV) and GOA concentrations. The data reveal that an increase in [Ce(IV)] as well as in [GOA] causes enhanced consumption of oxygen. Equally significantly, the data show that the oxygen consumption is approximately 10-30 times smaller than the total amount of reduced Ce(IV). The precise stoichiometric ratio $\left[\mathrm{O}_{2}\right]_{\text {consumed }}:[\mathrm{Ce}(\mathrm{IV})]_{\text {consumed }}$ depends on the initial values of [GOA] and [Ce(IV)]. Two characteristic examples of the temporal evolution of the oxygen concentration during the reaction are shown in Figure 4. From these data it is clear that the oxygen concentration decreases 


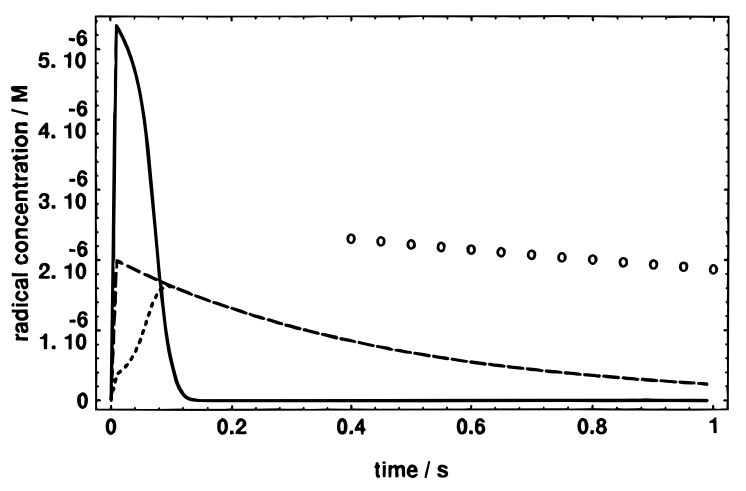

Figure 5. Typical example of the simulated time evolution of radical concentrations obtained on the basis of the standard autooxidation mechanism (cf. Introduction) including the anaerobic reactions R1 and $\mathrm{R} 2$. The dashed line represents the $\left[\mathrm{GOA}^{\circ}\right]$ under anaerobic conditions. Under aerobic conditions the model predicts the $\left[\mathrm{GOAO}_{2}{ }^{\circ}\right]$ and $\left[\mathrm{GOA}^{\circ}\right]$ kinetics as shown by the solid and dotted line, respectively. The circles represent experimental data for $\left[\mathrm{GOA}^{*}\right]$ under aerobic conditions.

slowly compared to the reduction of $\mathrm{Ce}(\mathrm{IV})$ and is therefore not directly influenced by this catalyst.

Theoretical Modeling. In order to obtain further clues to the mechanism for the observed, rather unusual, effect of radical decay inhibition by oxygen, we carried out theoretical modeling of the basic reaction kinetics. As a first step, we wanted to assess the extent to which standard autooxidation mechanisms (summarized in the Introduction) could explain the observed oxygen effect. All numerical simulations were performed by numerical integration of the underlying rate equations using the FACSIMILE program.

As outlined in the Introduction, it is known that in most autooxidation reactions a peroxy radical and its corresponding peroxide are formed. The peroxy radicals form from a fast reaction between the primary radical (here $\mathrm{GOA}^{\circ}$ ) with molecular oxygen. However, our EPR spectra revealed no evidence for the existence of $\mathrm{GOAO}_{2}{ }^{\circ}$. Possible explanations for our failure to detect the EPR signal from $\mathrm{GOAO}_{2}{ }^{\bullet}$ include the following: (1) $\mathrm{GOAO}_{2}{ }^{\bullet}$ is so short-lived that it reaches EPRdetectable concentrations only within the dead time of our EPR flow-experiment; (2) concentrations are below the detection limit during the whole course of the reaction, implying that although $\mathrm{GOAO}_{2}{ }^{-}$is formed, it undergoes a fast conversion to a nonradical species; (3) the formation of a peroxy radical is just not favored or is, at least, not a major pathway here. Notice, of course, that the explanations 1 and 2 explicitly require a reaction between the primary radical $\mathrm{GOA}^{\circ}$ and molecular oxygen, i.e., assume that the reaction follows the standard autooxidation pathway.

Numerical analyses were performed on the basis of the standard autooxidation mechanism including the anaerobic reaction steps (R1) and (R2). A typical example is shown in Figure 5, presenting the anaerobic and aerobic evolution of the radical concentration, dashed and dotted line, respectively. The formation of a peroxy radical (solid line) would inhibit the production of $\mathrm{GOA}^{\bullet}$ within the first $100 \mathrm{~ms}$. This time interval, however, was not resolved in our flow experiments. The crucial test for the standard model was to reproduce the observed temporal evolution of [GOA$\left.{ }^{*}\right]$ under aerobic conditions, shown by open circles in Figure 5. The depicted example reveals an irreconcilable discrepancy between the observed and calculated decay behaviors. On the basis of the results obtained by varying the rate constants systematically within broad intervals and their comparison with the experimental data, we conclude that this discrepancy is characteristic for the standard model. The involved reaction steps cannot reproduce an oxygen-induced
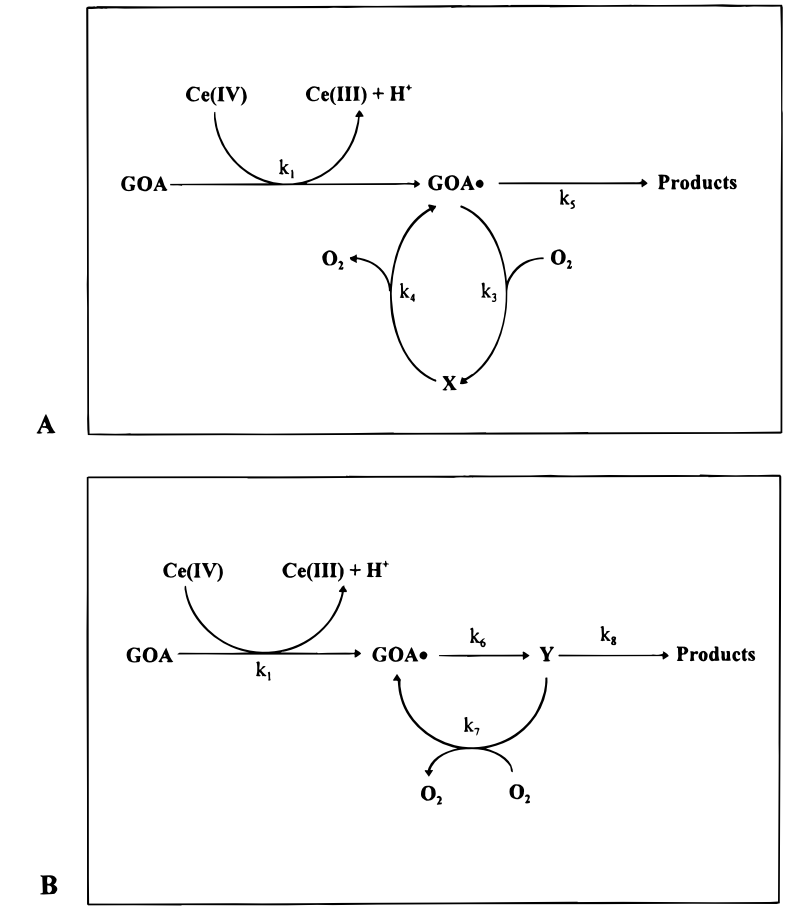

Figure 6. (A) Scheme of the modified standard autooxidation model that leads to an increase in $\left[\mathrm{GOA}^{\circ}\right]$ under oxygen atmosphere. The key process is the direct reaction of the primary radical with oxygen. The loop between $\mathrm{GOA}^{*}$, oxygen, and $\mathrm{X}$ represents an unknown reaction subset which could involve the peroxy radical and other intermediates. (B) Alternative reaction scheme which is capable of modeling the reported radical dynamics. The first stable intermediate of the primary radical decay, $\mathrm{Y}$, reacts with oxygen to efficiently produce the experimentally observed radical concentration. Similar to the oxygen involving reaction steps (R3, R4) in (A) the oxygen-catalyzed back reaction (R7) represents a possibly complex mechanism.

increase of [GOA${ }^{\bullet}$ : Typically, the aerobic decay of GOA ${ }^{\bullet}$ was nearly identical with the anaerobic behavior. In particular, the results showed no influence of oxygen on the rate of the GOA decay when simulations where performed with the expected, nearly diffusion-controlled, rate for the reaction between oxygen and GOA: Additional simulations of the observed oxygen consumption usually revealed very fast depletion that is not in agreement with the experimental data. We therefore conclude that the standard autooxidation mechanism is not even qualitatively capable of reproducing the experimental observations.

In order to help answer the query whether similar models can reproduce our EPR findings, we generalized the chain propagation reactions of the standard model. Since a fast depletion of oxygen obviously diminishes a possible inhibition process, we excluded oxygen-consuming reactions by modifying the second step of the propagation loop. However, the reaction between oxygen and the primary radical remains the key process of the oxygen effect on GOA:

$$
\begin{gathered}
\mathrm{GOA}+\mathrm{Ce}(\mathrm{IV}) \rightarrow \mathrm{GOA}^{\bullet}+\mathrm{Ce}(\mathrm{III})+\mathrm{H}^{+} \\
\mathrm{GOA}^{\bullet}+\mathrm{O}_{2} \rightarrow \mathrm{X} \\
\mathrm{X} \rightarrow \mathrm{GOA}^{\bullet}+\mathrm{O}_{2} \\
\mathrm{GOA}^{\bullet}+\mathrm{GOA}^{\bullet} \rightarrow \mathrm{P}
\end{gathered}
$$

A simple sketch of this mechanism is shown in Figure 6A. The loop between $\mathrm{GOA}^{\bullet}+\mathrm{O}_{2}$ and $\mathrm{X}$ represents an unknown reaction subset which includes the peroxy radical and possibly 


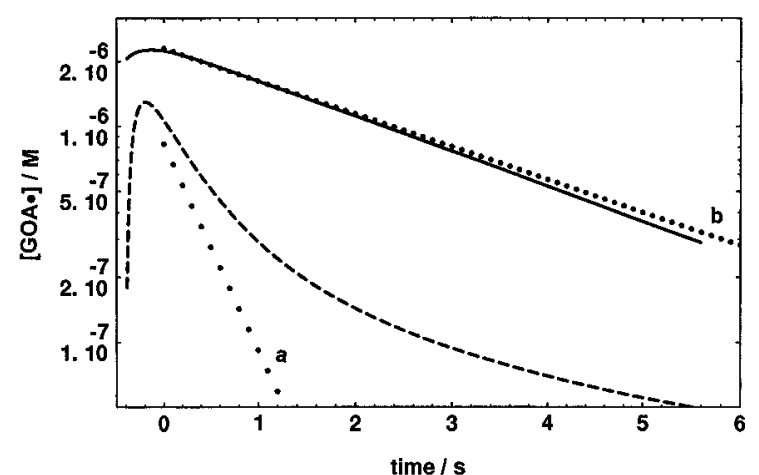

Figure 7. Comparison of the experimental data (dotted lines: (a) anaerobic, (b) aerobic conditions) of the radical kinetics to the simulated aerobic radical decay curves (solid line, Model B; dashed line, Model A) in a semilogarithmic presentation.

various other intermediates. Its rate constants correspond to the rate-limiting steps of this subset. Numerical simulations showed that additional reactions involving $\mathrm{Ce}(\mathrm{IV})$ are of minor relevance due to the low concentrations of the possible reaction species. A significant influence of $\mathrm{Ce}$ (III) (i.e., back reactions) was also ruled out, since addition of $\mathrm{Ce}$ (III) to the reaction mixture showed no significant effect in our spectrophotometric data.

A realistic model has to explain the observed inhibition of $\mathrm{GOA}^{*}$ decay under aerobic conditions. The dashed line in Figure 7 shows a typical logarithmic plot of the primary radical concentration as a function of time, obtained on the basis of the above model (rate constants $k_{3}=1 \times 10^{9} \mathrm{~L} \mathrm{~mol}^{-1} \mathrm{~s}^{-1}, k_{4}$ $\left.=500 \mathrm{~s}^{-1}, k_{5}=k_{2}=3.7 \times 10^{9} \mathrm{~L} \mathrm{~mol}^{-1} \mathrm{~s}^{-1}\right)$. During the first two seconds the concentration exhibits a fast decay governed by the anaerobic reaction dynamics. It is followed by a slower, nearly exponential, decay. Although the rate of this slower decay is consistent with the observed aerobic kinetics, the realized concentrations are too low and clearly not in agreement with the experimental data. Systematic simulations, testing the parameter space $\left(k_{3}, k_{4}\right)$ within the limits $10^{-2}$ and $10^{10}$, reveal that this class of reaction mechanisms (Figure 5a) is simply not capable of generating a fast transition to the observed slow exponential decay and thus cannot reproduce the measured radical concentration of $>2 \times 10^{-6} \mathrm{M}$. Again, these results emphasize the failure of standard autoxidation mechanisms to reproduce the measured oxygen-induced inhibition of the primary radical reactivity.

In the following, we suggest an alternative reaction scheme that readily models the reported radical dynamics (general structure shown in Figure 6B):

$$
\begin{gathered}
\mathrm{GOA}+\mathrm{Ce}(\mathrm{IV}) \rightarrow \mathrm{GOA}^{\bullet}+\mathrm{Ce}(\mathrm{III})+\mathrm{H}^{+} \\
\mathrm{GOA}^{\bullet}+\mathrm{GOA}^{\bullet} \rightarrow \mathrm{Y} \\
\mathrm{Y}+\mathrm{O}_{2} \rightarrow \mathrm{GOA}^{\bullet}+\mathrm{O}_{2} \\
\mathrm{Y} \rightarrow \mathrm{P}
\end{gathered}
$$

This mechanism postulates a reaction between oxygen and an unstable product of the $\mathrm{GOA}^{\bullet}$ dimerization. This product, the species $\mathrm{Y}$ in the above reaction scheme, could be a precursor or unstable conformation of the expected recombination product tetrahydroxysuccinic acid (THSA). Our preliminary results show that the disodium salt of THSA, a substance that was first reported in 1885 by Miller, decays under the given experimental conditions ( $1 \mathrm{M} \mathrm{H}_{2} \mathrm{SO}_{4}$ ) on a time scale of many hours. ${ }^{25-28}$ Its self-decay is therefore not relevant for our fast EPR experiments. Similar to the oxygen-involving reactions in (R3) and (R4), the oxygen-catalyzed back reaction (R7) represents a possibly complex mechanism. The solid line in Figure 7 shows the radical decay calculated on the basis of the above model using the rate constants $k_{6}=k_{2}=3.7 \times 10^{9} \mathrm{~L} \mathrm{~mol}^{-1} \mathrm{~s}^{-1}, k_{7}=$ $6.6 \times 10^{3} \mathrm{~L} \mathrm{~mol}^{-1} \mathrm{~s}^{-1}, k_{8}=0.75 \mathrm{~s}^{-1}$ and an oxygen concentration of $1 \mathrm{mM}$. This curve is in excellent agreement with the experimental data obtained under aerobic conditions. We note that the model is also consistent with the described anaerobic radical decay, and it violates neither the measured stoichiometry nor the observed Ce(IV) kinetics. However, it does not consider the consumption of oxygen. Since the consumption is small and fairly slow, it seems likely that an intermediate of the reaction loop between $\mathrm{Y}$ and $\mathrm{GOA}^{*}$ involves an additional pathway, controlling the oxygen depletion process.

\section{Discussion}

This study establishes that the anaerobic oxidation of glyoxylic acid by $\mathrm{Ce}(\mathrm{IV})$ in $1 \mathrm{M}$ sulfuric acid can indeed be described by the two reactions (R1) and (R2). While this conclusion is in agreement with the earlier studies,${ }^{3}$ the present investigation identifies for the first time the involved radical and furthermore reports the rate constants $k_{1}$ and $k_{2}$. The analysis of $k_{2}$ was based on the result that the anaerobic kinetics of $\mathrm{GOA}^{\bullet}$ follow a second-order self-decay that obeys a steadystate approximation. It is reasonable, however, to assume that the reaction step (R2) consists of at least two irreversible reaction steps in which a dimer of the primary radical occurs as an intermediate. In this context $k_{2}$ has to be considered as the rate constant of the dimer formation.

According to standard autoxidation mechanisms, oxidation reactions that are initiated by the formation of carbon-centered radical species and exposed to molecular oxygen are generally assumed to form peroxy radicals at an almost diffusioncontrolled rate. So far, however, only a few peroxy radicals of small organic molecules have been directly identified. This fact is generally explained in terms of low concentration and fast decay of this species. Our experiments show no evidence for the formation of the peroxy radical $\mathrm{GOAO}_{2}{ }^{\circ}$. Furthermore, exposure of the reaction mixture to oxygen does not lead to quenching of the primary radical but rather to the opposite effect: Oxygen causes a significant decrease of the experimental decay constant of the primary radical disappearance (Figure 3). On the basis of our theoretical analysis as presented in the previous section, we can conclude that the general model of autoxidation processes fails to describe these experimental results. Accordingly, the formation of a possible peroxy radical cannot lead to the observed fast increase of the $\mathrm{GOA}^{*}$ concentration, under aerobic conditions. This result strongly supports our suggestion that certain organic acids like GOA must follow a fundamentally different reaction mechanism. The scheme presented in Figure $6 \mathrm{~b}$ can explain our experimental results. The main feature of this mechanism is the oxygencatalyzed reaction of the first intermediate that is formed by the radical decay process. While the exact identity of this intermediate (species labeled $\mathrm{Y}$ in Figure 6b) remains to be elucidated, the proposed scheme readily reproduces the observed increase in $\left[\mathrm{GOA}^{\circ}\right]$ and the observed decrease in experimental rate constants.

The investigated reaction system shows, for example, remarkable contrast to the recently reported free-radical chemistry of the ceric oxidation of malonic acid. ${ }^{14}$ In the malonic acid system, molecular oxygen was considered as a fast kinetical switch, influencing mainly the kinetics of $\mathrm{Ce}$ (IV) and the peroxymalonyl radical. The slow decay of the primary malonyl radical revealed therefore no significant dependence on the initial 
oxygen concentration. The elucidation of the detailed structure of aerobic reaction pathways for small organic acids is therefore an important challenge for future studies. The results could have the potential for revealing a different aerobic oxidation mechanism. Also the role of glyoxylic acid in the complex oxidation of malonic acid and related cross reactions are of interest for future studies. A thorough knowledge of these reaction mechanisms should furthermore provide a better understanding of oxygen effects ${ }^{8-11}$ and aging ${ }^{29,30}$ in the selforganizing Belousov-Zhabotinsky reaction.

The comparison of the aerobic radical mechanisms during the $\mathrm{Ce}(\mathrm{IV})$ oxidation of glyoxylic and malonic acid gives rise to another intriguing question of general importance: What are the structural differences between these two organic molecules that cause the observed, significant differences in their reaction pathways and radical kinetics? This question provides, in itself, ample reason for further systematic studies on the aerobic oxidation of organic acids and the necessary accumulation of additional data.

Acknowledgment. This research was supported by the Deutsche Forschungsgemeinschaft, the U.S. Department of Energy, and the Florida State University. O.S. thanks the Fonds der Chemischen Industrie for a Liebig Fellowship.

\section{References and Notes}

(1) Richardson, W. H. In Organic Chemistry, Blomquist, A. T., Ed.; Academic Press: New York, 1965; Vol. 6, Part A, Wiberg, K. B., Ed.; Chapter IV, p 244.

(2) Willard, H. H.; Young, P. J. Am. Chem. Soc. 1930, 52, 132.

(3) Jwo, J.-J.; Noyes, R. M. J. Amer. Chem. Soc. 1975, 97, 5422.

(4) Gao, Y.; Försterling, H.-D.; Noszticzius, Z.; Meyer, B. J. Phys. Chem. 1994, 98, 8377.

(5) Zaikin, A. N.; Zhabotinsky, A. M. Nature 1970, 225, 535.

(6) Field, R. J., Burger, M., Eds. Oscillations and Traveling Waves in Chemical Systems; Wiley-Interscience; New York; 1985.

(7) Försterling, H.-D.; Stuk, L. J. Phys. Chem. 1991, 95, 7320.
(8) Försterling, H.-D.; Stuk, L. J. Phys. Chem. 1991, 96, 3067.

(9) Barkin, S.; Bixon, M.; Noyes, R. M.; Bar Eli, K. Int. J. Chem. Kinet. 1978, 10, 619. 47.

(10) Zhabotinsky, A. M.; Müller, S. C.; Hess, B. Physica D 1991, 49 ,

(11) Zhabotinsky, A. M.; Györgyi, L.; Dolnik, M.; Epstein, I. R. J. Phys. Chem. 1994, 98, 7981.

(12) Treindl, L.; Fabian, P. Collect. Czech. Chem. Commun. 1980, 45 , 1168.

(13) Ruoff, P.; Noyes, R. M. J. Phys. Chem. 1989, 93, 7394.

(14) Neumann, B.; Müller, S. C.; Hauser, M. J. B.; Steinbock, O.; Simoyi, R. H.; Dalal, N. S. J. Am. Chem. Soc. 1995, 117, 6372.

(15) Howard, J. A. In Free Radicals; Kochi, J. K., Ed.; Wiley: New York, 1973; Vol. II, Chapter 12, p 3.

(16) Kaner, R. J.; Epstein, I. R. J. Am. Chem. Soc. 1978, 100, 4073.

(17) Ruoff, P.; Hansen, E. W.; Noyes, R. M. J. Phys. Chem. 1987, 91, 3393.

(18) Steenken, S.; Sprague, E. D.; Schulte-Frohlinde, D. Photochem. Photobiol. 1975, 22, 19.

(19) Samuni, A.; Behar, D.; Fessenden, R. W. J. Phys. Chem. 1973, $77,777$.

(20) Brusa, M. A.; Perissinotti, L. J.; Colussi, A. J. J. Phys. Chem. 1985, $89,1572$.

(21) Sadtler Research Laboratories, Division of Bio-Rad Laboratories, USA; 1980, C 2998.

(22) Howard, J. A. In Landolt-Börnstein, Neue Serie, II/9c2; Fischer, H., Hellwege, K.-H.; Eds.; Springer: Berlin, 1979; p 5. In LandoltBörnstein, Neue Serie, II/17e; Fischer, H., Ed.; Springer: Berlin, 1988; p 5.

(23) Czapski, G.; Levanon, H.; Samuni, A. Isr. J. Chem. 1969, 7, 375.

(24) Samuni, A.; Czapski, G. J. Phys. Chem. 1970, 74, 4592.

(25) Miller, W. L. Ber. Deutsch. Chem. Ges., Berlin 1889, 22, Jahrgang, 2015.

(26) Fenton, H. J. M. J. Chem. Soc. 1895, 67, 48.

(27) Müller, E., Ed. Houben-Weyl: Methoden der organischen Chemie, 4th ed.; Georg Thieme Verlag: Stuttgart, 1973; Volume VII/2a Ketone Teil I, pp 758-759.

(28) Markovic, V.; Sehested, K.; Bjergbakke, E. Int. J. Radiat. Phys. Chem. 1973, 5, 15.

(29) Krüger, F.; Nagy-Ungvarai, Zs.; Müller, S. C. Physica D 1995, 84,95 . 15.

(30) Nagy-Ungvarai, Zs.; Ungvarai, J.; Müller, S. C. Chaos 1993, 1,

JP960300W 